\title{
I'm the One: Social Media, Social Identity, and Elections
}

\author{
Jason Anthony Cain ${ }^{{ }^{*}}$ \\ (iD) 0000-0003-3091-4754 \\ ${ }^{1}$ University of Mississippi, USA \\ ${ }^{*}$ Corresponding author: jacain@olemiss.edu
}

Citation: Cain, J. A. (2020). I'm the One: Social Media, Social Identity, and Elections. Online Journal of Communication and Media Technologies, 10(4), e202025. https://doi.org/10.30935/ojcmt/9142

\begin{tabular}{|c|c|}
\hline ARTICLE INFO & ABSTRACT \\
\hline Received: 23 Jun 2020 & This study surveyed voters to investigate why they shared political information on social media \\
\hline Accepted: 12 Aug 2020 & $\begin{array}{l}\text { during the } 2016 \text { election. A strong social identity informed by political alignment was found to } \\
\text { predict both polarization and more sharing, while feeling politically misaligned was found to } \\
\text { decrease information sharing, supporting a spiral of silence phenomenon. Those with higher } \\
\text { scores on a scale of social identity were more likely to feel sharing information to be an } \\
\text { influential activity. }\end{array}$ \\
\hline
\end{tabular}

Keywords: social identity, social media, political communication

\section{INTRODUCTION}

The 2016 presidential election seemed one of the more acrimonious in recent times. Many news and political commentary outlets speculated where the bitterness of the campaigns placed the 2016 election historically (Barone, 2016; Cummins, 2016). Where the negative discourse of the 2016 election places it when compared to other election cycles will probably remain a conversation for political scientists and historians for decades, but there is no denying that Donald Trump and Hillary Clinton were the two least popular candidates to run for the office since such statistics have been kept (Collins, 2016; Enten, 2016).

Many factors undoubtedly played a role in Trump and Clinton's ultimately arriving at the top of the ticket, but social media platforms certainly found themselves taking a great deal of the blame. NPR posed the question, “Did media ruin election 2016?" (Sanders, 2016), a headline just after the election for a story that concluded "...we end this campaign season with social media platforms seemingly hardwired for political argument, obfuscation and division. We are a public more concerned with scandal than policy, at least according to the social media data," (Sanders, 2016, p. 32).

How much social media are to blame for the level of discord in the 2016 election is up for debate, but there is no arguing that social media play a huge role in feeding America's news consumption. Gottfried and Shearer (2016) found that $62 \%$ of adults reported reading news on social media. To that end, what this research concerns itself with is not the effect social media may or may not have had on the election, noting that by any measure it is a major player in news dissemination, but why people share what political content that they did online. Using social identity theory and spiral of silence as theoretical underpinnings, this research seeks to demonstrate that what most social media participants expected from sharing political content was not furthering a conversation or a debate but to reinforce group identity. If this is indeed the case, it argues that perhaps social media are not a marketplace of ideas as much as an ideological battleground where content becomes rallying flags for those engaged in political warfare.

Copyright $(\mathbf{2 0 2 0}$ by authors; licensee OJCMT. This article is an open access article distributed under the terms and conditions of the Creative Commons Attribution License (http://creativecommons.org/licenses/by/4.0/). 


\section{LITERATURE REVIEW}

\section{Social Identity Theory}

Social identity theory (SIT) predicts that an individual's group affiliations contribute to their overall identity, a group being defined as, "....a collection of individuals who perceive themselves to be members of the same social category, share some emotional involvement in this common definition of themselves, and achieve some degree of social consensus about the evaluation of their group and of their membership of it" (Tajfel, Turner, Austin, \& Worchel, 1979, p. 40). Tajfel et al. describe several expectations derived from this prediction. One with a great deal of bearing on the current study states, "Positive social identity is based to a large extent on favorable comparisons that can be made between the in-group and out-groups: the in-group must be perceived as positively differentiate or distinct from the relevant out-groups" (Tajfel et al., 1979, p.40).

By definition, political parties exist to harness the political power of like-minded individuals into a cohesive platform in order to compete with other groups which espouse differing ideas on the various issues facing the electorate (Riker, 1982). While the political landscape in the United States is comprised of more than two political parties, at this point in time, the Republican and Democratic parties continue to dominate this landscape, particularly in elections where representatives to the national government are being chosen.

In his seminal work on group dynamics, Sherif (1988) found that once groups have formed, competition for goals in which one group must necessarily be the winner and the other the loser proved a suitable catalyst for intergroup hostility. These hostile interactions ranged from stereotyping to threats of physical violence from one group to the next. Like the children in the Robber Cave Experiment (Sherif, 1988), The Democratic and Republican parties are in electoral competition where the success of one group necessarily means the defeat of another. After all, only one candidate can ultimately win a position.

As Sherif's (1988) research might predict, this particular election was peppered with not only stereotyping from both sides, but even outright violence (Holland, 2016; Rhodes, 2016). Looking at 2016 through the lens of SIT, one can't help but question what role in-group behavior and maintaining a positive identity within that group must have played. Furthermore, Sherif (1988) provides support to the notion that in a presidential election, wherein the goal is the most powerful office in the United States (and arguably the world), hostility is to be expected.

The hopes for communication on the internet are still relatively well encapsulated in Chaffe and Metzger's 2001 piece "The End of Mass Communication," which asserts that the diversity of voices allowed on the internet might allow for new groups to grow and serve as vehicle to find more likeminded individuals, additionally speculating what this means for the future of mass communication theory as the audience and media channels become myriad and stratified. In a general sense, some later research has found the internet's upsetting mass communication to be somewhat muted, noting that "Our review shows that although theories may change to accommodate the changes of the new media environment, researchers are still dealing with the 'old' issues of power and resistance, and structure and ownership" (Weimann, WeissBlatt, Mengistu, \& Tregerman, 2014, p. 822). While the discussion should be continued, there remains evidence that perhaps, to quote The Who, it's a bit of "Meet the new boss, same as the old boss" (Townshend, "Won't Get Fooled Again, 1971).

More specific to this study, there is evidence that social media are far more a catalyst for creating a rather homogenous media diet at the expense of dialectic. In Hazel and Samuel-Azran's 2016 study of secondscreeners - television viewers who simultaneously engage online with the subject they are watching - that social media seem predominately used by posters of political content to reinforce likeminded views.

Another study focusing on the role hostile media theory plays in shaping audience opinions of the mainstream media and their subsequent media selection by more partisan citizens found that social media use seemed to mitigate the hostile media effect, possibly due to users tending to use such media to reinforce positive group identity (Lin, Haridakis, \& Handson, 2016). While these researchers linked this to earlier work by Lazarsfeld, Berelson, and Gaudet (1944), the connection to Tiajfel's (1982) SIT research in that intragroup interactions tend to reinforce positive characterizations of the group are clear. Other social media research examining online commenting noted the social penalty paid by posters who stepped beyond the established 
social norms of a group face a barrage of acrimony for their troubles (Rost, Stahel, \& Frey, 2016), supporting the notion of social identity at work online and group reinforcement trumping debate.

SIT has been applied to political research in the past. Research by Greene (1999) found "that American citizens do have social identifications with political parties and that identifications substantively affect their political perceptions and partisan behavior" (p. 402). Lupu (2015) suggested in work examining partisanship that social-identity would be a natural driver of partisanship as groups sought to highlight intergroup differences. Most salient to the current study, Ponder and Haridakis (2015) found in-group and out-groups dynamics play a role in media selection. Interestingly, while news commentary programming on television acted as an opinion leader for political groups who aligned with their hosts, seeming to correlate to discussions within groups, as well as between them, "political blogs and microblogs were a negative predictor of discussion with political out-group members" (Ponder \& Haridakis, 2015, p. 297). This supports the notion that at least in some areas online, users share political information to reinforce group identity, not to create dialectic between differing views.

In light of past studies connecting SIT to both social media and politics, the following hypothesis and research questions are proposed.

H1 Scores that are more polar on a scale of liberal/conservative attitudes will correlate to higher scores on a scale of social identity.

H2 Higher scores on the Organization Identification Scale (OIS) will predict increased sharing of political content.

RQ1 Will scores on the Conservatism-Liberalism Scale (CLS) match self-reported political affiliation for (a) all respondents and (b) respondents who posted political content on social media during the 2016 election?

RQ2 Were there any predictors of someone sharing political information on social media, and if so, are social identity, political attitude, or political polarization among those predictors?

RQ3 Is there a correlation between scores on a scale of social identity and a scale of political identity?

RQ4 Do scores on scales of social identity and/or political identity correlate to hours spent on social media; belief that sharing political information influenced others; plans to share more political information in the future, or a belief that information shared by others had an effect on how a respondent voted?

\section{Spiral of Silence}

Spiral of Silence (SOS) dictates that "[the mass media] provide the environmental pressure to which people respond with alacrity, or with acquiesce, or with silence" (Noelle-Neumann, 1974, p. 51). According to the theory, a person who feels that he or she holds a minority opinion is much less likely to express that opinion than if he or she feels that his or her personal views align with mainstream thought. In this fashion, the theory predicts that contradicting opinion will largely be self-censored, creating a feedback loop that only deepens the perception of the dominance of mainstream opinion.

SOS research focused its attention on traditional media originally, predicting that the more one consumed of traditional media the more these media would shape their perception of public opinion and subsequent expression of personal opinions perceived to not align with public opinion in face-to-face discussion (NoelleNeumann, 1981). Obviously, internet communication presents a very different dynamic, both in how it has diversified media channels through which a person might gather information and how that person might express opinion. Studies done prior to the explosion of social media indeed found spiral of silence's predictive power somewhat muted if not completely absent in online communication (Ho \& McLeod, 2008; McDevitt, Kiousis, \& Wahl Jorgensen, 2003; Wanta \& Dimitrova, 2000). It should be noted though that these studies all involved the use of internet chat rooms, bulletin board systems, or simply using the internet to remotely conduct a focus group. None involved an examination of social media and the effect perceptions of opinion among a user's connection might shape their interactions on those platforms.

Metzger (2009) acknowledged that spiral of silence's future seemed poor in many online contexts due to user's ability to find and interact with content that was better suited to their views, and yet she made specific 
mention of Facebook and LinkedIn as areas ripe for research informed by spiral of silence theory. There has been some support for the theory in later research online. Gearhart and Zhang (2014) found users of social network sites, a type of social media, were reluctant to express opinions on those sites that they felt dissented from popular opinion on the issue of gay bullying. Yun and Park (2011) found that those who felt their opinion was in the minority tended to express themselves less frequently online. These studies create some reason to continue investigating the theory in regard to social media.

In the context of the present study, SOS presents a useful counterpoint to trying to better understand why people post political information in that it gives a theoretical basis as to why a social media user may not post. In order to test the prediction that those who perceive themselves to be in the minority will also tend to speak less, the current study offers one final hypothesis:

H3 Respondents who feel their beliefs to be deviant to that of their connection on social media will be less likely to post political content in the future.

\section{METHOD}

To test these hypotheses and research questions, a survey instrument was administered to gather information about social media users who shared political content during the 2016 presidential election. A survey instrument was chosen for this research due to its utility in collecting large amounts of data generalizable data on respondents in a timely fashion (Barker, 1989). Additionally, much of the past research that informed this study used a survey method. The scales used from prior research or constructed using rationale guided by past research were thus best suited for use in this survey method study (Mehrabian, 1996, Mael \& Ashforth, 1992).

\section{Sample \& Data Collection}

Participants in this study were recruited through use of Amazon's Mechanical Turk service (MTurk). MTurk provides a way to crowd-source participants across the internet in order to engage with a broader audience that is broader than student samples often used for research at a university (Mason \& Suri, 2012). Further studies have documented the utility of this platform for empirical research both compared to other methods of survey distribution (Casler, Bickel, \& Hackett, 2013) and compared to other methods for survey sampling (Clifford, Jewell, \& Waggoner, 2015; Huff \& Tingley, 2015).

Respondents who participated in the survey were invited through an MTurk Human Intelligence Task (HIT) request posted on the MTurk site to take an online survey designed in Qualtrics, an online software package that allows for the design and administration of surveys over the Internet. Respondents were compensated $\$ 0.75$ for their time for a completed survey. Screening questions asking whether a respondent was eligible to vote in the United States and if he or she used social media were asked to ensure that respondents could vote if they wished and did use social media. Additionally, measures to prevent multiple surveys from the same respondent were used both within MTurk and the Qualtrics software, such as not allowing users who had already accepted the HIT from taking it again and IP tracking. Techniques such as reversing scale direction for items in matrix questions or embedding directions to select a specific answer within a large body of text were employed to help reduce selection bias and screen for inattentiveness (Oppenheimer, Meyvis, \& Davidenko, 2009).

This study design also took into account recent ethical concerns over using mTurk workers in addition to the methodological consideration inherent in sampling any population. Most of these concerns involve the exploitation of "Turkers," mTurk respondents (Williamson, 2016; Harris, 2014). Workers were paid roughly minimum wage as the survey took five to ten minutes to complete for a payment of $\$ 0.75$. Additionally, in this particular study, all workers who emailed reporting that something transpired that prevented them from receiving or being able to enter their specific verification code were still paid despite failing to do so. Finally, steps were taken in the survey directions to inform respondents before starting the questionnaire that they must be at least 18 years old, eligible to vote in the United States, social media users, and that careful and attentive reading of all questions would be required. It was stated that failing to meet these criteria would result in an incomplete survey and that they would not be compensated as such. 
Table 1. Respondents by Education, Income, and Ethnicity

\begin{tabular}{|c|c|c|c|c|c|c|c|c|}
\hline Education & $\%$ & $n$ & Income & $\%$ & $n$ & Ethnicity & $\%$ & $n$ \\
\hline Some High School & 1.0 & 3 & $0-\$ 20 k$ & 27.7 & 86 & White/Non-Hispanic & 77.1 & 239 \\
\hline High School or GED & 10.6 & 32 & Over $\$ 20 k-\$ 40 k$ & 31.3 & 97 & Hispanic or Latino & 6.8 & 21 \\
\hline Some College Credit & 20.2 & 63 & Over $\$ 40 k-\$ 60 k$ & 14.8 & 46 & Black or African Am. & 5.8 & 18 \\
\hline Trade/Technical/Voc. & 3.2 & 10 & Over $\$ 60 k$ - $\$ 80 k$ & 12.3 & 38 & Asian & 8.4 & 26 \\
\hline Associates Degree & 10.9 & 34 & Over $\$ 80 \mathrm{k}-\$ 100 \mathrm{k}$ & 8.1 & 25 & Other & 1.9 & 6 \\
\hline Bachelor's Degree & 42.9 & 134 & Over $\$ 100 k-\$ 120 k$ & 4.2 & 13 & & & \\
\hline Master's Degree & 8.0 & 24 & Over $\$ 120 \mathrm{k}-\$ 140 \mathrm{k}$ & 1.0 & 3 & & & \\
\hline Professional Degree & 1.9 & 6 & Over \$140k & .6 & 2 & & & \\
\hline Doctorate Degree & 1.3 & 4 & & & & & & \\
\hline Total & 100 & 310 & & 100 & 310 & & 100 & 310 \\
\hline
\end{tabular}

The survey was first pretested, changes made where needed, and the final questionnaire then created. Filter questions were used to ensure only respondents eligible to vote in the United States who used social media participated. Respondents who either did not consent to the survey, did not use social media, or were not eligible to vote in the United States were not allowed to complete the survey.

The survey remained open from February 10 - 27, 2017, after which results were compiled. After closing the survey, the data were cleaned in Microsoft Excel, a software spreadsheet platform, and then uploaded into SPSS, statistical analysis software, for analysis. Only responses to demographic, psychographic, level of use, and Likert-Scale questions were used in analysis. Once all of the steps were taken to ensure the accuracy of the data entered into SPSS, as well as the confidentiality of the respondents, data analysis began.

The total $n$ was 328 , though 16 responses were excluded for failure to complete the survey. Responses were further filtered to only include respondents that reported sharing political posts on social media between August 1, 2016 (after both parties' national conventions were over) and the election on November 8, 2016. The final $n$ was 310 completed surveys. Males comprised $56.7 \%(n=176)$ of respondents and females $42.3 \%(n=131)$ with $1 \%(n=3)$ preferring not to say or answering other. When asked about their political affiliation, 50\% ( $n=155)$ answered that they were Democratic. Of the remaining, 21.5\% $(n=67)$ responded that they were Republican and $28.5 \%(n=88)$ Other/Independent. The average age of respondents was 37.27 $(S D=12.22)$. Table 1 contains a breakdown of respondents by level of education, income, and ethnicity.

\section{Scales}

In order to determine political perspective, the current research employs Mehrabian's (1996) Conservatism-Liberalism Scale (CLS). This scale consists of seven statements with nine scale points in regard to political attitudes. The current research reduced the scale points from nine to five to as it was felt five points would adequately indicate a respondent's attitude. Statements are both positive and negative in order to check for reliability between answers. Mehrabian and other researchers directly spent the better part of a decade refining this scale and took into account nearly some 40 years' worth of research into measuring political attitudes. (Mehrabian, 1996). Table 2 contains these statements. To calculate a respondent's overall score, the scores for individual items were added together to create a composite score. Mean scores marked with an asterisk indicate the reversed mean as these questions indicate a shift toward liberal leanings politically as the scale number increased, unlike the other four questions where a lower score indicated political leanings more in line with being a liberal.

Mael and Ashforth's (1992) Organization Identification Scale (OIS) was used to measure the level to which a respondent's political party corresponded to an aspect of his or her social identity. This scale represents a distillation of past scales measuring similar attitude into one, six-item scale for determining the role group identity plays in conceptualizing one's social identify. While it was first employed to measure attitudes one holds toward their school, the scale was intended to be modified for measuring a respondent's identification with any group as a way to measure social identity. Accordingly, the scale in this study has been modified to elicit attitudes toward how strongly group identity reverberates when a respondent considers the political party he or she sees as most representative of them. The statements used are in Table 3. To calculate a respondent's overall score, the scores for individual items were added together to create a composite score. This scale was also reversed for all variables marked with an asterisk in order that an increased organization 
Table 2. Organization Identification Scale Items

\begin{tabular}{|c|c|c|c|}
\hline & Statement & Mean & SD \\
\hline 1. & I am politically more liberal than conservative. & 2.46 & 1.58 \\
\hline 2. & $\begin{array}{l}\text { In any election, given the choice between a Republican and a Democratic candidate, I will } \\
\text { select the Republican over the Democrat. }\end{array}$ & $2.38^{*}$ & 1.48 \\
\hline 3. & Communism has been proven to be a failed political ideology. & $3.81 *$ & 1.24 \\
\hline 4. & I cannot see myself ever voting to elect conservative candidates. & 2.98 & 1.55 \\
\hline 5. & The major national media are too left-wing for my taste. & $2.76^{*}$ & 1.47 \\
\hline 6. & Socialism has many advantages over capitalism. & 2.95 & 1.31 \\
\hline 7. & On balance, I lean politically more to the left than to the right. & 2.53 & 1.51 \\
\hline
\end{tabular}

Table 3. Organizational Identification

\begin{tabular}{llcc}
\hline & Statement & Mean & SD \\
\hline 1. & When someone criticizes this political party, it feels like a personal insult. & $2.61^{*}$ & 1.23 \\
2. & I am not interested in what others think about this political party. & 3.19 & 1.20 \\
3. & When I talk about this political party, I usually say "we" rather than "they." & $2.65^{*}$ & 1.24 \\
4. & The successes of this political party are my successes. & $2.88^{*}$ & 1.29 \\
5. When someone praises this political party, it feels like a personal compliment & $2.50^{*}$ & 1.19 \\
6. If a story in the media criticized this political party, I would not feel embarrassed. & $2.48^{*}$ & 1.25 \\
\hline
\end{tabular}

identification aligned with a higher score. Item 2 was reversed in Mael and Ashforth's original scale and was not revered here for that reason.

\section{Variables}

The CLS and OIS will be used as independent variables (IV) in determining if they were predictors of sharing information on social media during the 2016 presidential election. Other IVs will include the demographic and psychographic variables described above in the sample, self-reported party identity, and estimated political leanings of those in a respondent's social network.

Dependent variables (DV) in this study include how often a respondent shared posts about the 2016 presidential election, whether a respondent believed people who agreed or disagreed with the content of one of his or her posts would be more likely to benefit from that post, the CLS in the case of H5, and self-reported party identity in the case of R1. A DV measuring Political Polarization was calculating by taking the CLS scale and recoding such that the middle of the scale became 1 on the polarization scale and actual distance from that scale, whether positive or negative on the scale itself, moved up. For example, on the original scale, 1 represented having the most liberal attitude possible, while a 5 represented the most conservative attitude possible. In the scale of political polarization, both of these scale points would become a 3, as the interest is not whether a respondent leaned positive or negative but how far from the center a respondent measured. Additionally, a question was asked as to whether or not a respondent shared information at all. This question served as a filter when it was appropriate to only use "yes" and "maybe" responses for some variables in hypothesis testing.

\section{RESULTS}

\section{Research Questions}

RQ1 asked whether self-reported political affiliation would show an association with CLS scores for (a) the entire survey sample and (b) only respondents that reported definitely sharing political content during the elections. For both parts, a one-way between subjects ANOVA was conducted to compare the effect of grouping by self-reported party affiliation on the mean scores of the CLS.

For RQ1a, a significant difference between mean scores (Figure 1) on the CLS when grouped by political affiliation was demonstrated by the one-way $\operatorname{ANOVA}[F(2,307)=232.01, p<.01]$. Post hoc comparisons using the Tukey HSD test indicated that the mean score for Democratic $(M=14.80, S D=4.26)$ was significantly lower $(p<.05)$ than both the Independent/Other $(M=19.93, S D=7.10)$ and Republican groups $(M=31.31, S D=4.37)$. Also, of note is that the mean score for Independent/Other was also significantly lower $(p=.05)$ than the Republican group. 


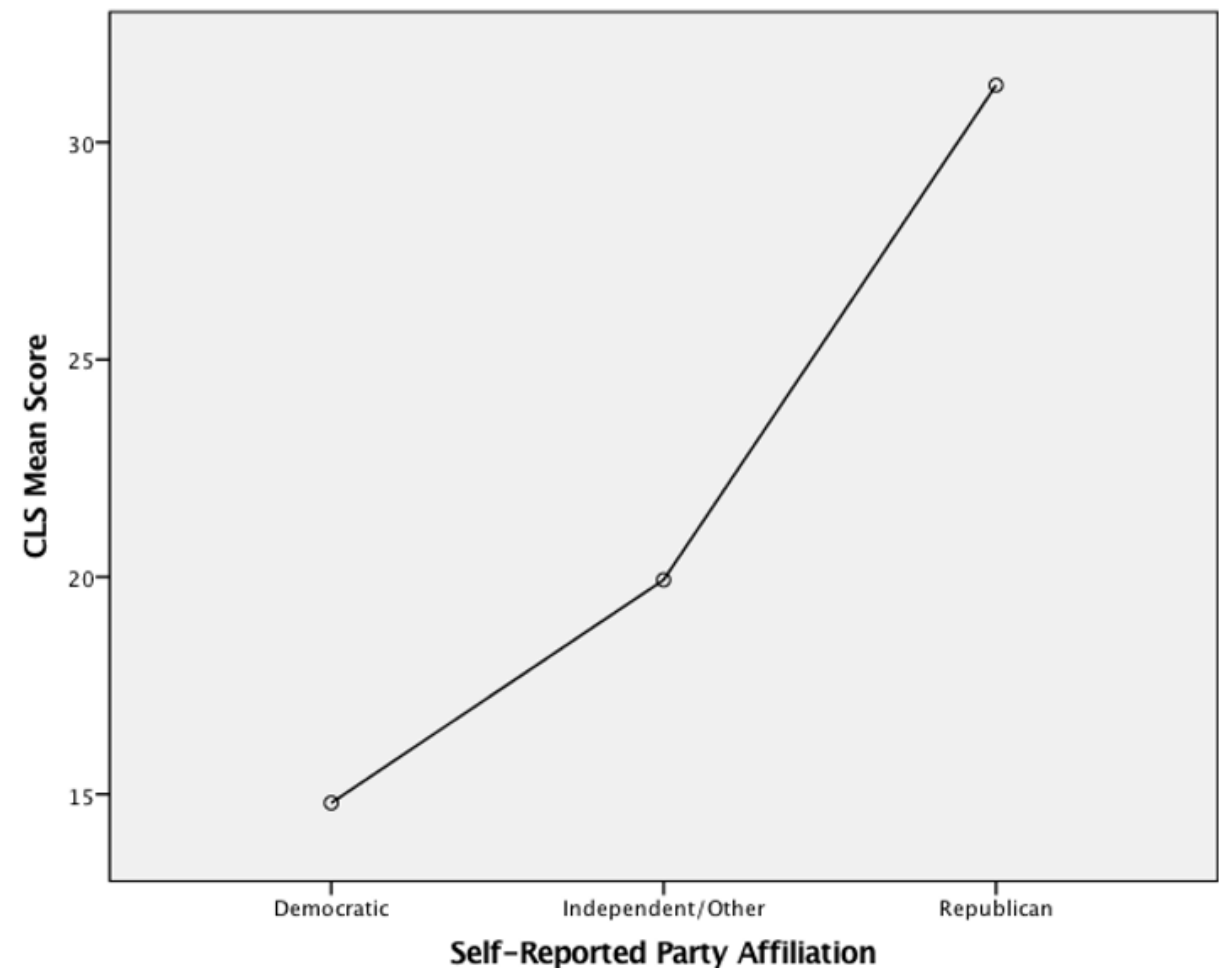

Figure 1. ANOVA of Self-Reported Party Affiliation and CLS Score for All Respondents

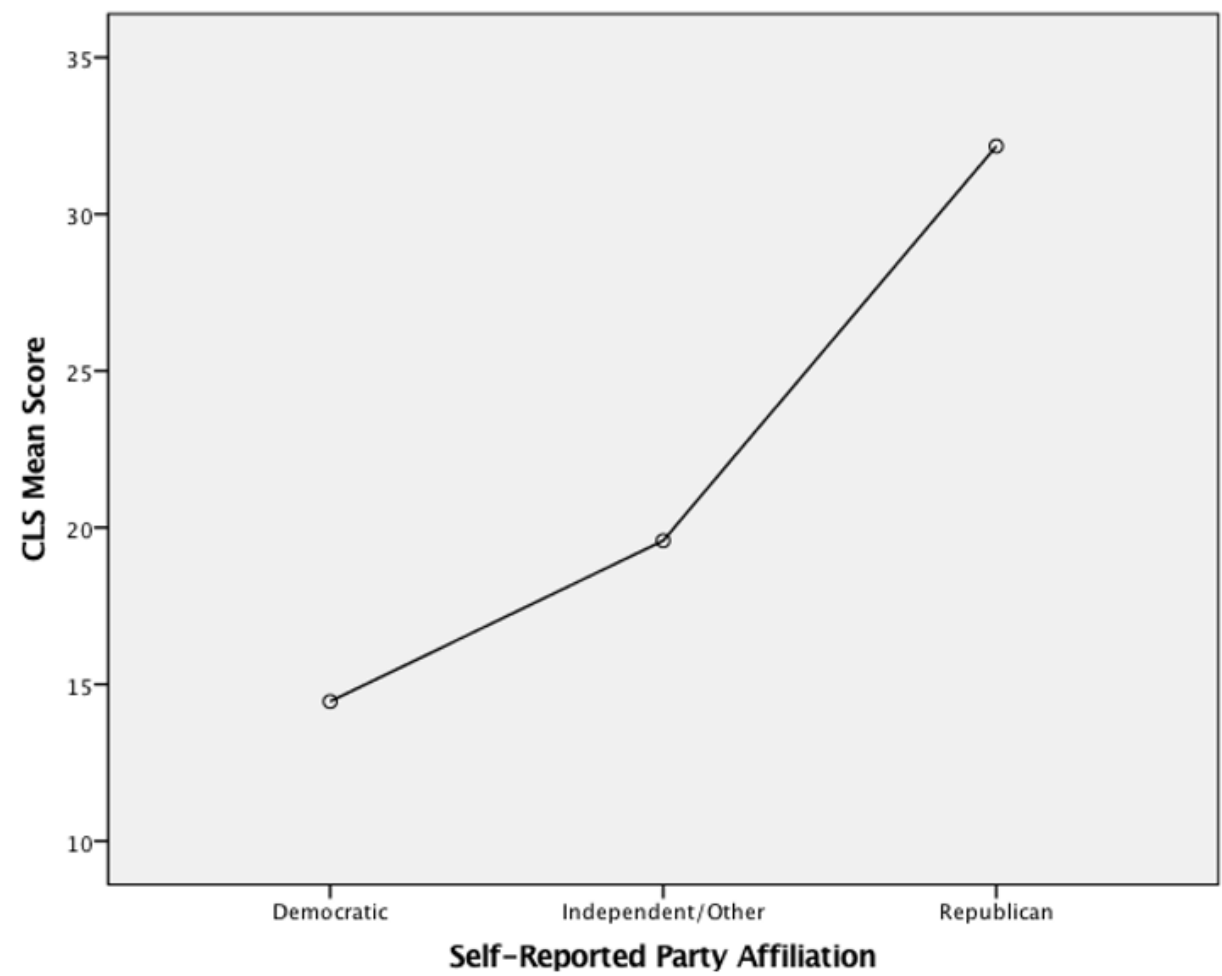

Figure 2. ANOVA of Self-Reported Party Affiliation and CLS Score for Posters

For RQ1b, a significant difference between mean scores (Figure 2) on the CLS when grouped by political affiliation was demonstrated by the one-way $\operatorname{ANOVA}[F(2,181)=157.26, p<.01]$. Post hoc comparisons using the Tukey HSD test indicated that the mean score for Democratic $(M=14.45, S D=4.29)$ was significantly lower $(p<.05)$ than both the Independent/Other $(M=19.58, S D=7.84)$ and Republican groups $(M=32.17, S D=3.71)$. Again, the mean score for Independent/Other was also significantly lower $(p=.05)$ than the Republican group. 
For the next three research questions, a filter question was used to screen out respondents who did not share political content on social media during the election $(n=184)$ in order to focus specifically on the data for respondents who actively shared content during the 2016 presidential campaign.

RQ2 asked if there were there any predictors of someone sharing political information on social media, and if so if social identity, political attitude, or political polarization among those predictors. A hierarchical linear regression was conducted in order to examine predictors of sharing political information during the 2016 election. Block one contained variables for gender, ethnicity, education, party affiliation, and age. None of these variables were significant predictors of sharing political information during the election. The second block added the CLS, OIS, and Political Polarization scores to the model. OIS scores $(\beta=.16, p<.01)$ and Political Polarization $(\beta=.19 p<.01)$ both showed significant associations with sharing political content. These results support that only political polarization and social identity predict the sharing of political content on social media, also answering the question as to what predicts sharing and demonstrating that polarization but not affiliation predicts sharing as well.

RQ3 asked if there a correlation between scores on a scale of social identity and a scale of political identity. Pearson product-moment correlation coefficient was computed between the OIS and CLS scales showing no correlation between the two and thus no particular correlation between being more liberal or more conservative and having a stronger sense of social identity.

RQ4 sought to investigate what social media behaviors correlated to higher scores on the OIS scores used to measure political social identity. Significant positive correlations were found between OIS scores and believing political content shared influenced others $[r=.30, n=184, p<.01]$, being influenced by others in a respondent's social network $[r=.28, n=184, p<.01]$, and sharing more political content in the future $[r=.20$, $n=184, p<.01]$. No correlation was found for hours spent on social media.

\section{Hypotheses}

H1 asserted that higher scores on the Political Polarization variable would correlate to higher scores on the OIS used to determine a respondent's level of social identity derived from his or her political affiliation. A Pearson product-moment correlation coefficient was computed between the two variables demonstrating a positive correlation between Political Polarization and scores on the OIS $[r=0.19, n=310, p<.01]$. These results support a significant correlation between political polarization and social identity in the context of party identity.

To test H2, which asserted that higher scores on the OIS would result in an increased sharing of political content, a one-way between subjects ANOVA was conducted to compare the effect of grouping by posting frequency and the mean scores of the OIS (Figure 3). A significant difference between mean scores on the

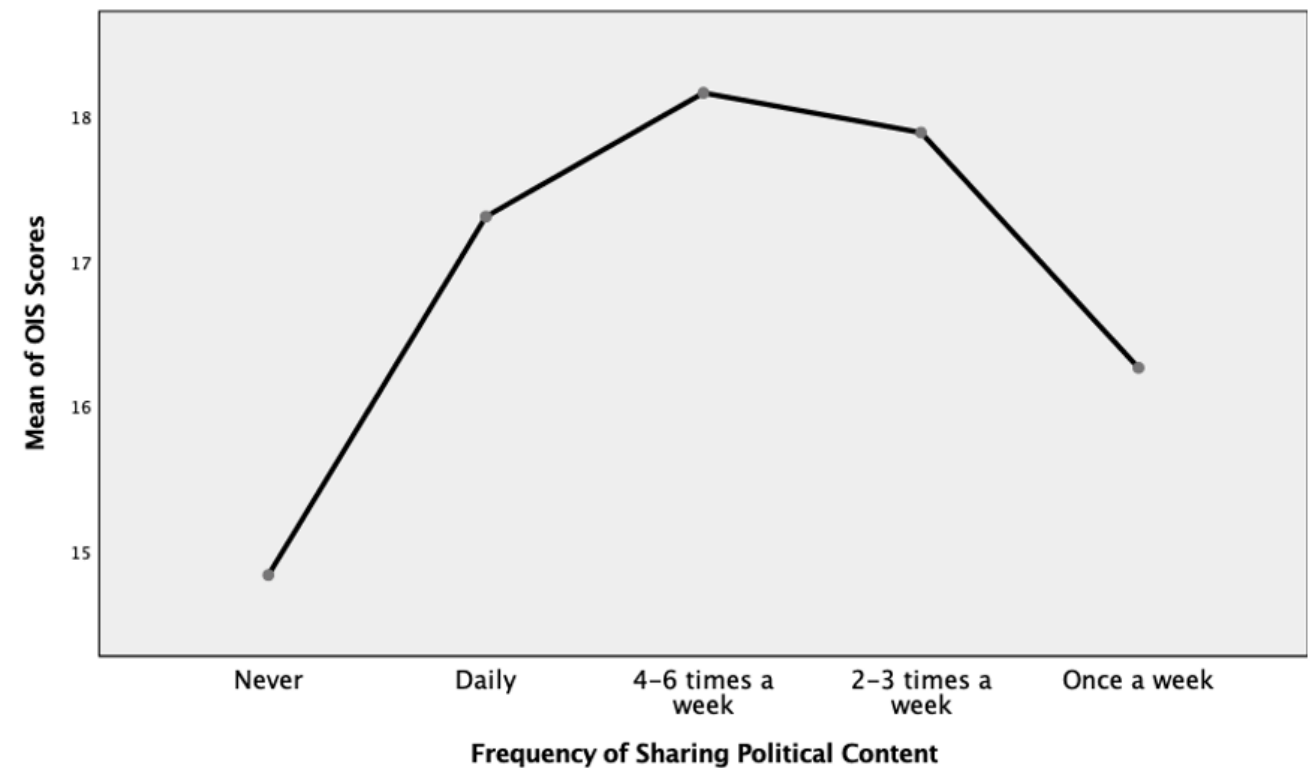

Figure 3. ANOVA of OIS Score and Sharing Frequency 
OIS when grouped by posting frequency was demonstrated by the one-way ANOVA $[F(4,299)=4.55, p<.01]$. Post hoc comparisons using the Tukey HSD test indicated that the mean score for Never $(M=14.84, S D=4.72)$ was significantly lower $(p<.05)$ than both the 4-6 Times a Week Group $(M=18.16, S D=5.30)$ and the 2-3 Times a Week Group $(M=17.89, S D=4.85)$. Daily $(M=17.31, S D=5.80)$ and Once a Week $(M=16.26, S D=5.07)$ also had higher mean scores, but not significantly so. Taken together, these results support $\mathbf{H 2}$.

H3 proposed that respondents who felt their own political beliefs to be different from there connections on social media would be less likely to post political information in the future. A screening question first filtered out respondents who did not share political information during the election. For the remaining participants $(n=212)$, a Pearson product-moment correlation coefficient was computed for respondents who answered that they shared political content and planned to share political content in the future and if he or she believed his or her political beliefs aligned with their connection on social media and demonstrated a significant negative correlation between the two $[r=-0.19, n=212, p<.01]$.

\section{DISCUSSION}

RQ1 functioned as a reliability check between how respondents self-reported political identity and their score on Mehrabian's (1996) Conservatism-Liberalism Scale. Political identity served as a primary variable for this study, so it seemed only logical to test if respondents would self-identify on the same ends of the political spectrum as they scored on the CLS. Also, as the study was primarily interested in respondents who shared political posts during the 2016 during the 2016 election, RQ1 was split into two questions to determine first if the entire sample and next if only those who shared political information would share an association between their self-reported political identity and the CLS. It was found that for both the entire sample and among only those that shared political content that mean scores on the CLS grouped significantly as expected by political affiliation, with the lower scoring respondents reporting to be Democratic and higher scoring respondents reporting to be Republicans. Interestingly, the Independent/Other category fell in between in both cases as well, indicating that in this sample, those who considered themselves to be in this category were also the most moderate group. Overall, it supports the reliability of Mehrabrian's (1996) CLS within the present study and its utility for future studies.

Moving on, RQ2 examined which variables would predict the sharing of political information online. After controlling for gender, ethnicity, education, party affiliation, and age, only Political Polarization and scores on the OIS were determined to significantly predict sharing. While this supports that the greater a respondent exhibited a sense of social identity based on party affiliation the more likely he or she was to share, perhaps of most interest is that being more liberal of conservative had no predictive power. However, being on the polar end in either direction did predict sharing, supporting that there is no break along party lines for this behavior. Based on the results, whether one is to the left or the right, sharing behavior increases as a respondent's polarization increased.

In an effort to determine if perhaps party and social identity correlated, RQ3 asked if whether there was a correlation between the CLS and OIS, and none was found. This follows the trend found with RQ2 where it seems the power of party identification to facilitate the creation of social identity doesn't break along party lines. To that end, $\mathbf{H} \mathbf{1}$ proposed that political polarization would correlate to higher OIS scores, which it in fact did. Taking the results of RQ2, RQ3, and $\mathbf{H} \mathbf{1}$ together, this suggests that rather than the liberal/conservative dichotomy through which politics tends to be framed, the real dichotomy is between extremism and moderation.

This supports previous research (Greene, 2016; Lupu, 2015) and is important, as it indicates that viewing online politics as the left vs. the right might be missing what the real conversation is - the extremes on either side rallying one another and dictating the tone of the conversation happening. Lupe (2015) mentions socialidentity as a driver of partisanship, and extremism in politics could be argued to be a kind of ultrapartisanship. Therefore, it makes sense that being an ultra-partisan - for either party - correlates to higher level of social-identity taken from those parties.

RQ4 explored which social media behaviors significantly correlated to higher OIS scores. Respondents with higher OIS scores believed that their sharing activities influenced others and were influenced by others in their social network. While no significant correlation was found between increased use of social media, 
those with higher scores did report be more likely to share more political content in the future. Overall, respondents who seemed to take a greater sense of identity from their party affiliation seemed to believe that political content's ability to influence was greater than those with lower scores.

When these results are considered with the others discussed thus far, a concerning possibility arises. Among these respondents, polarization and social identity correlate to one another. Likewise, as social identity also corresponds to sharing behavior and a belief in its efficacy, it's not a jump in logic to assume that the political content we see now and in the future on our social networks will be generated by the most polarized elements of those networks to whom we are connected. To that end, $\mathbf{H} \mathbf{2}$ asserted that higher OIS scores would correlate to increased sharing behavior during the election, an assertion that was ultimately supported. This seems to indicate that those with the strongest sense of identity relating to party ties shared the most content during the election, just as other results indicate this trend should move forward in the future.

Finally, $\mathbf{H 3}$ proposed that those who felt their personal politics were misaligned with the politics of their online social networks would be less likely to share political content in the future, which indeed is the case. These results argue that while social identity and polarization lead to more political activity on social networks, voices that might form a dissenting counterbalance are less likely to speak up and shows further support for past studies applying spiral of silence theory to online spaces (Gearhart \& Zhang, 2014, Yun \& Park 2011). Should these results indeed be an accurate reflection of the public at large, it seems the future of social media politics may increasingly be one where extreme voices dominate, left somewhat unchecked by dissenting voices within their own bubbles.

In looking back at the Ponder and Haridakis (2015) study where the researchers discovered blogging frequency to negatively correlate to cross-party political discussion, RQ4 and $\mathbf{H} \mathbf{3}$ might be evidence of the same behavior taking place on social media. More politically polarized respondents did seem to believe that political information they shared and consumed online to be influential, but overall in this study, people who felt to be the political deviant on their online social networks tended to post less information. It stands to reason, based on that finding, those posting were posting among perceived confederates and not attempting to create a dialectic online but possibly as a way of maintaining the identity of their political in-group.

\section{Limitations \& Future Research}

While MTurk samples tend to be broader than student samples (Mason \& Winter 2011) and have demonstrated utility (Casler, Bickel, \& Hackett, 2013), there remains a convenience sample aspect to the method. Future research making use of randomly sampled panels to investigate this same area might provide more robust results either supporting or contradicting these findings. Additionally, regardless of sampling procedures, revisiting these questions of identity and politics and how they influence online behaviors should remain a regular endeavor by any researchers working in these areas. While it may be cliché at this point to say the online world evolves rapidly, it remains a fact and an important one. Where online communication and social media are going continue to be an open question, as are their implications on social structures such as government. As chaotic as Twitter, Facebook, and other platforms may seem, they are in truth young platforms still in many respects, and even should they fall out of favor with the public, online culture fueled by social connectivity will more than likely only grow more important, regardless of platform. To this end, continued study in this area, further refining questions posed by this study and others that have preceded it, may prove key in discerning where human society is going as connectivity between all of us deepens.

\section{CONCLUSION}

Issues surrounding the use of social media post 2016 have, if anything intensified, with the ramifications platforms like Facebook and Twitter may have on the current election still of concern. If discourse is indeed a key function of a healthy democratic republic, the implications of identity and polarization on the flow of information on social media must be of concern. This is not to cry that the sky is falling; simply, this study and others continue to build a case for the balkanization of online communication. While platforms continue to emerge and die, internet denizens acting as content creators, gatekeepers, and consumers through their online networks will continue to exist in one form or another. Likewise, these networks will continue to exhibit 
influence on how society functions to some degree, and given the penetration and growth of social media, more than likely a large one. It is therefore necessary to deepen our understanding of our tendency to fragment into spaces where our opinions and worldview are never challenged if there is any hope of subverting that urge and enriching these spaces into the healthy public squares that they could possibly be. This research presents more support for the lack of diverse, robust online dialectic, but that doesn't mean it is impossible. As stated earlier, social media are still young, and we are only just now understanding the positive and negative influence they may be. With better understanding also comes the hope that the positive potential of social media may be realized in the future.

\section{REFERENCES}

Baker, D. (1989). Language testing: A critical survey and practical guide. Arnold.

Baron, E. (2016). This writer ranked American history's dirtiest elections. Here's what he says about 2016. Time Magazine. Retrieved from https://time.com/4554784/dirtiest-elections-american-history-2016/

Casler, K., Bickel, L., \& Hackett, E. (2013). Separate but equal? A comparison of participants and data gathered via Amazon's MTurk, social media, and face-to-face behavioral testing. Computers in Human Behavior, 29(6), 2156-2160. https://doi.org/10.1016/j.chb.2013.05.009

Chaffee, S. H., \& Metzger, M. J. (2001). The end of mass communication?. Mass communication \& society, 4(4), 365-379. https://doi.org/10.1207/S15327825MCS0404_3

Clifford, S., Jewell, R. M., \& Waggoner, P. D. (2015). Are samples drawn from Mechanical Turk valid for research on political ideology?. Research \& Politics, 2(4). https://doi.org/10.1177/2053168015622072

Collins, E. (2016). Poll: Clinton, Trump most unfavorable candidates ever. USA Today, 31. Retrieved from https://www.usatoday.com/story/news/politics/onpolitics/2016/08/31/poll-clinton-trump-mostunfavorable-candidates-ever/89644296/

Cummins, J. (2016). This Is the Dirtiest Presidential Race Since'72. Politico Magazine, 17.

Enten, H. (2016). Americans' distaste for both Trump and Clinton is record-breaking. Five Thirty Eight. Retrieved from https://fivethirtyeight.com/features/americans-distaste-for-both-trump-and-clinton-is-recordbreaking/

Gottfried, J., \& Shearer, E. (2016). News Use Across Social Medial Platforms 2016. Pew Research Center.

Greene, S. (1999). Understanding party identification: A social identity approach. Political Psychology, 20(2), 393-403. https://doi.org/10.1111/0162-895X.00150

Harris, M. (2014). Amazon's Mechanical Turk workers protest:'l am a human being, not an algorithm.'. The Guardian, 3. Retrieved from https://www.theguardian.com/technology/2014/dec/03/amazonmechanical-turk-workers-protest-jeff-bezos

Hayat, T., \& Samuel-Azran, T. (2017). "You too, Second Screeners?" Second Screeners' Echo Chambers During the 2016 US Elections Primaries. Journal of Broadcasting \& Electronic Media, 61(2), 291-308. https://doi.org/10.1080/08838151.2017.1309417

Ho, S. S., \& McLeod, D. M. (2008). Social-psychological influences on opinion expression in face-to-face and computer-mediated communication. Communication Research, 35(2), 190-207. https://doi.org/10.1177/0093650207313159

Holland, S. (2016). Violence again convulses 2016 election campaign, testing Trump, Clinton. Reuters. Retrieved from https://www.reuters.com/article/us-usa-police-politics/violence-again-convulses-2016-electioncampaign-testing-trump-clinton-idUSKCNOZO2LJ

Huff, C., \& Tingley, D. (2015). "Who are these people?" Evaluating the demographic characteristics and political preferences of MTurk survey respondents. Research \& Politics, 2(3). https://doi.org/10.1177/2053168015604648

Lazarsfeld Paul, F., Berelson, B., \& Gaudet, H. (1944). The People's choice. New York: Duell, Sloan, and Pearce.

Lin, M. C., Haridakis, P. M., \& Hanson, G. (2016). The role of political identity and media selection on perceptions of hostile media bias during the 2012 presidential campaign. Journal of Broadcasting \& Electronic Media, 60(3), 425-447. https://doi.org/10.1080/08838151.2016.1203316

Lupu, N. (2015). Party polarization and mass partisanship: A comparative perspective. Political Behavior, 37(2), 331-356. https://doi.org/10.1007/s11109-014-9279-z 
Mael, F., \& Ashforth, B. E. (1992). Alumni and their alma mater: A partial test of the reformulated model of organizational identification. Journal of organizational Behavior, 13(2), 103-123. https://doi.org/10.1002/job.4030130202

Mason, W., \& Suri, S. (2012). Conducting behavioral research on Amazon's Mechanical Turk. Behavior research methods, 44(1), 1-23. https://doi.org/10.3758/s13428-011-0124-6

McDevitt, M., Kiousis, S., \& Wahl-Jorgensen, K. (2003). Spiral of moderation: Opinion expression in computermediated discussion. International Journal of Public Opinion Research, 15(4), 454-470. https://psycnet.apa.org/doi/10.1093/ijpor/15.4.454

Mehrabian, A. (1996). Relations among political attitudes, personality, and psychopathology assessed with new measures of libertarianism and conservatism. Basic and Applied Social Psychology, 18(4), 469-491. https://doi.org/10.1207/s15324834basp1804_7

Metzger, M. J. (2009). The study of media effects in the era of Internet communication. Conference Papers -International Communication Association, 1-31.

Noelle-Neumann, E. (1974). The spiral of silence a theory of public opinion. Journal of communication, 24(2), 43-51. https://doi.org/10.1111/j.1460-2466.1974.tb00367.x

Oppenheimer, D. M., Meyvis, T., \& Davidenko, N. (2009). Instructional manipulation checks: Detecting satisficing to increase statistical power. Journal of Experimental Social Psychology, 45(4), 867-872. https://doi.org/10.1016/j.jesp.2009.03.009

Ponder, J. D., \& Haridakis, P. (2015). Selectively social politics: The differing roles of media Use on political discussion. Mass Communication and Society, 18(3), 281-302. https://doi.org/10.1080/15205436.2014.940977

Rhodes, J. (2016). Violence has long been a feature of American elections. TheConvesation.com. Retrieved from http://theconversation.com/violence-has-long-been-a-feature-of-american-elections-67688

Riker, W. H. (1982). Liberalism against populism (Vol. 34). San Francisco: WH Freeman.

Rost, K., Stahel, L., \& Frey, B. S. (2016). Digital social norm enforcement: Online firestorms in social media. PLoS one, 11(6), e0155923. https://doi.org/10.1371/journal.pone.0155923

Sanders, S. (2016). Did social media ruin election 2016?. National Public Radio.

Sherif, M. (1988). The robbers cave experiment: Intergroup conflict and cooperation.[Orig. pub. as Intergroup conflict and group relations]. Wesleyan University Press.

Tajfel, H. (1982). Human groups and social categories. 1981. Taijfel and Turner," The Social Identity Theory of Intergroup Behavior, 7-24. https://psycnet.apa.org/doi/10.4324/9780203505984-16

Tajfel, H., Turner, J. C., Austin, W. G., \& Worchel, S. (1979). An integrative theory of intergroup conflict. Organizational identity: A reader, 56-65.

Townshend, P. (1971). Won't Get Fooled Again [Recorded by The Who]. On Who's Next, London: Track.

Wanta, W., \& Dimitrova, D. (2000). Chatrooms and the spiral of silence: An examination of online discussions during the final 1996 US presidential debate. International Communication Association, Acapulco, Mexico.

Weimann, G., Weiss-Blatt, N., Mengistu, G., Tregerman, M. M., \& Oren, R. (2014). Reevaluating "The end of mass communication?". Mass Communication and Society, 17(6), 803-829. https://doi.org/10.1080/15205436.2013.851700

Williamson, V. (2016). Can Crowdsourcing Be Ethical?. Brookings Institution, 3.

Woong Yun, G., \& Park, S. Y. (2011). Selective posting: Willingness to post a message online. Journal of Computer-Mediated Communication, 16(2), 201-227. https://doi.org/10.1111/j.1083-6101.2010.01533.x

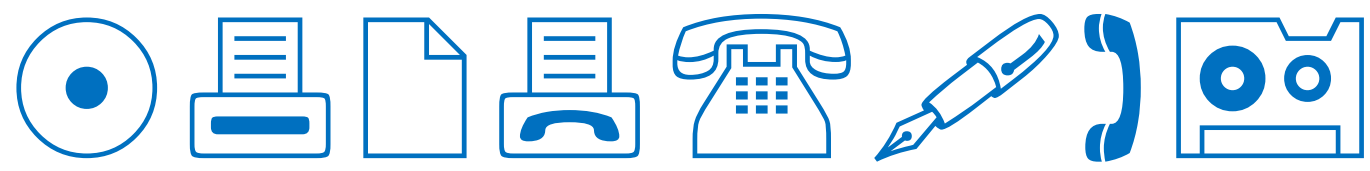

